\title{
Dizaltı alçı, dizüstü alçı, patellar tendon taşıyıcı (PTB) alçı uygulamaları
}

\section{Above knee casting, below knee casting, and patellar tendon bearing casting}

\author{
Bülent Tanrıverdi, Mustafa Gökhan Bilgili
}

Bakırköy Dr. Sadi Konuk Eğitim ve Araştırma Hastanesi, Ortopedi ve Travmatoloji Kliniği, İstanbul

\begin{abstract}
Alçılama ve konservatif tedavi günümüzde uygun hastaların tedavisinde halen güncelliğini koruyan tedavi seçenekleridir. Bu yöntemlerin 'olmazsa olmaz'ı uygulama sırasında temel prensiplere mutlaka riayet edilmesinin gerekliliğidir. Bu bölümde, ortopedi pratiğinde sıklıkla kullanılan dizüstü, dizaltı ve patellar tendon taşıyıcı alçılama tekniklerinden bahsedilecektir.
\end{abstract}

Anahtar sözcükler: dizüstü; dizaltı; alçı
Casting and conservative treatment are still current orthopaedic treatment modalities in appropriate patients. The "sine qua non" of those methods is strict application of basic principles. In this section, above knee, below knee, and patellar tendon bearing casting techniques will be discussed.

Key words: above knee; below knee; casting

birlikte, daha hafif ve radyolusen olması nedeniyle fiberglas alçılar da sıklıkla kullanılmaktadır. ${ }^{[1]}$

Alçı tedavisi, çoğunlukla ağrının yönetimi ve çok ciddi olmayan kırıklarda hareket etmeyi kolaylaştırmak için kullanılır. Konservatif veya cerrahi tedavi kararı, sıklıkla hastanın yaşı, fiziksel durumu, mental durumu, kırık öncesi hareket kapasitesi gibi birçok faktöre bağlıdır. ${ }^{[1]}$

$\mathrm{Bu}$ bölümde, alt ekstremite kırıklarının konservatif tedavisinde kullanılan dizaltı alçı, dizüstü alçı ve patellar tendon destekli (PTB) alçı tekniklerinden bahsedilecektir.

\section{ALÇININ UYGULANMASI}

Alt ekstremite için kullanılması daha uygun olan alçı ölçüsü, hastanın yaşı ve anatomisine göre, genelde eni $10-15 \mathrm{~cm}$ genişliğinde olan alçılardır. Eğer sentetik bir alçı tercih edilecekse 10-12,5 cm genişliğindeki alçılar kullanılabilir. Alçı, içinde sargı yüksekliğini aşacak kadar su bulunan bir su kabının içerisine daldırılır. Su içerisinde oluşan hava baloncuklarının sonlanması beklenir. Sonrasında, ıslak alçı iki el arasında uçlarından ortasına doğru gevşek olarak

- İletişim adresi: Op. Dr. Bülent Tanrıverdi, Bakırköy Dr. Sadi Konuk Eğitim ve Araştırma Hastanesi Ortopedi ve Travmatoloji Kliniği, Zuhuratbaba mah., Tevfik Sağlam cad., No: 11, Bakırköy, İstanbul Tel: 0212 - 4147171 e-posta: drbulenttanriverdi@gmail.com

- Geliş tarihi: 1 Ağustos 2018 Kabul tarihi: 1 Ağustos 2018 
sıkıştırılır ve içerisindeki fazla suyun çıkması sağlanır. Alçı hiçbir zaman çamaşır sıkar gibi farklı yönlere burulmamalıdır.

Dizaltı ya da dizüstü alçı uygulanmadan önce, gereklilikler eksiksiz bir şekilde tamamlanmış olmalıdır. Hasta, etkilenen alt ekstremitesi muayene masasından aşağıya sarkacak şekilde oturtulmalı, alçıyı uygulayacak hekim hastanın tam karşısında olacak şekilde pozisyon almalı ve alçı için kullanılacak uygun ölçülerdeki malzemeler (alçı çorabı, pamuk, alçı rulosu, soğuk su kovası, yerin kirlenmesini önleyecek kâğıt ya da plastik örtü, alçı sonrası bacağı desteklemek için kullanılacak yastık) hazırlanmış olmalıdır. Yine, kırık yerleştirmesinin uygun olmadığı durumlarda alçıyı ya da kamayı çıkartabilmek için gerekli olan malzemeler de (alçı makası, alçı motoru, genişletici, bistüri) önceden hazırlanmış olmalıdır.

illk alçı uygulamalarında, sirküler alçının uygulanması esnasında, alçının altının çok fazla desteklenmesinin kırıkta redüksiyon kaybına neden olduğu, çok az desteklenmesinin ise cilt problemleri ve artmış kompartman riski ile ilişkili olabileceği sonucuna varılmıştır. Günümüzde, redükte edilmiş bir kırık alçılanırken sekonder deplasmanlardan kaçınmak için fazla pedleme yapılmamalıdır. Alçı, ciltte katlantı oluşturmadan, düzgün bir şekilde uygulanmalıdır. Ekleme uygun açıdaki pozisyon verilerek alçı yapılmalıdır. Alçı sonrası kırı̆̆ın kabul edilebilir pozisyonunu koruduğundan emin olmak için direkt grafi çekilmelidir. İnstabil kırıkların alçı ile tedavisi sırasında daha yakın takip yapılmalıdır. Kallus oluşup kırığı tespit edene dek seri takipler yapılmalıdır. ${ }^{[1]}$

Alçı uygulanmadan önce, yer değiştirmiş kırıklarda kırık uçları anatomik olarak kabul edilebilir sınırlarda yerleştirilmelidir. Yerleştirme sonrası uzunluk, açılanma ve rotasyon kusurları giderilmiş olmalıdır. Kırığın yerleştirmesi ek yaralanmaya neden olmayacak bir biçimde nazikçe yapılmalıdır. Bu amaçla, kas kontraksiyonunu ortadan kaldırabilmek için anestezi altında yerleştirme yapılması, uygun şartlar altında tercih edilmelidir. Yine, zorlayıcı manevraların kırık komşuluğundaki damar, sinir ve diğer yumuşak dokulara zarar verebileceği unutulmamalıdır. Kırık uçları arasına çevre yumuşak dokunun girebileceği ve redüksiyona engel olabileceği unutulmamalıdır. Yine, gecikmiş ve hematomun fazla olduğu kırıklarda da yerleştirme manevraları başarısız olabilir. Yer değiştirmemiş kırıklarda direkt alçı uygulamasına geçilebilir.

Kırığın yerleştirilmesi, tercihen lokal ya da genel anestezi altında, ekstremitenin masadan aşağıya sarkıtılmasıyla yapılmalıdır. Dizin fleksiyona getirilmesi gastroknemius-soleus kompleksinin gevşemesini sağlayarak, hem rotasyonun kontrolünü kolaylaştırır hem de ayak bileğinin nötral pozisyonunun daha kolay verilmesini sağlar. Ayak bileği ve topuktan uygulanan traksiyonla kırık uçları arasındaki kısalık giderilmiş olur (Şekil 1). Yerleştirme için, kırık oluşum mekanizmasının aksi yönünde manipülasyonlar uygulanır. Bu işlemi yaparken, ek yumuşak doku yaralanmasına neden olunmamasına özen gösterilmelidir. Yerleştirmenin kalitesi, tibial krestin proksimal ve distaldeki devamlılığının palpasyonla kontrolü ile test edilebilir. Rotasyon kontrolü için, ayak aksı - uyluk açısı (Şekil 2) ve kırık ekstremitenin karşı ekstremiteyle olan uyumu değerlendirilmelidir. Rotasyon için kullanılan bir diğer değerlendirme yöntemi de patella - 1. parmak arasındaki dizilimin superior ve anteriorda normal şekilde sağlanmasıdır. Bu dizilim anatomik olarak sağlandığında, tibianın sahip olduğu normal dış rotasyon da sağlanmış olur. Uygun redüksiyonu yapılmış bir tibia kırığında, kruris lateralde konveks, mediyalde konkav bir yüze sahip olmalıdır ve uygulanan alçı da benzer bir görünümde olmalıdır (Şekil 3).

Alçı uygulanması sırasında, ayağın aşırı dorsifleksiyonunun rekurvatuma (apeks posterior açılanma), plantar fleksiyonun ise prokurvatuma (apeks anterior açılanma) neden olabileceği unutulmamalıdır. Diyafiz kırıklarında anguler açılanma, alçıya kama açılarak düzeltilebilir. Bu teknikte, radyografi veya tercihen floroskopi kullanılarak, kırık hattından alçının 2-3 cm'si dayanak noktası olarak bırakılarak, gerekli düzeltme yapılabilir. Redüksiyonun uygun olduğu pozisyonda, yine alçı sarılarak redüksiyon pozisyonunun devamı sağlanmaya çalışılır. Bu yöntemle, teorik olarak, alçı sirküler kesilerek rotasyonel bozukluklar da düzeltilebilir. Ancak, bu durumda pozisyon kaybı olabilir ve bazen alçıyı çıkarıp yeniden yapmak daha iyi bir tercih olabilir. İnstabil kırıklarda alçı ile redüksiyonunun sağlanamadığı durumlarda, alçı ile tedavide ısrar edilmemeli ve cerrahi tedavi planlanmalıdır. ${ }^{[1]}$

Sirküler alçı yapımında dikkat edilmesi gereken hususlar şunlardır ${ }^{[2]}$ :

- Hastaya yapılacak işlemler açıklanır.

- Alçı yapılacak ekstremiteye uygun pozisyon verilir. Hasta sandalyeye oturtulur ya da alçı masasına yatırılır.

- Kırık redüksiyonu (gerekirse anestezi altında) yapilır.

- Herhangi bir yara veya abrazyon varsa temizlenir ve akıntılı bölgeler not edilir.

- Alçı pamuğu gevşek ve düzgün olacak şekilde, kırışıklık oluşturmadan ve her bir tur diğerinin \%50'sini örtecek şekilde sarılır (Şekil 4). 


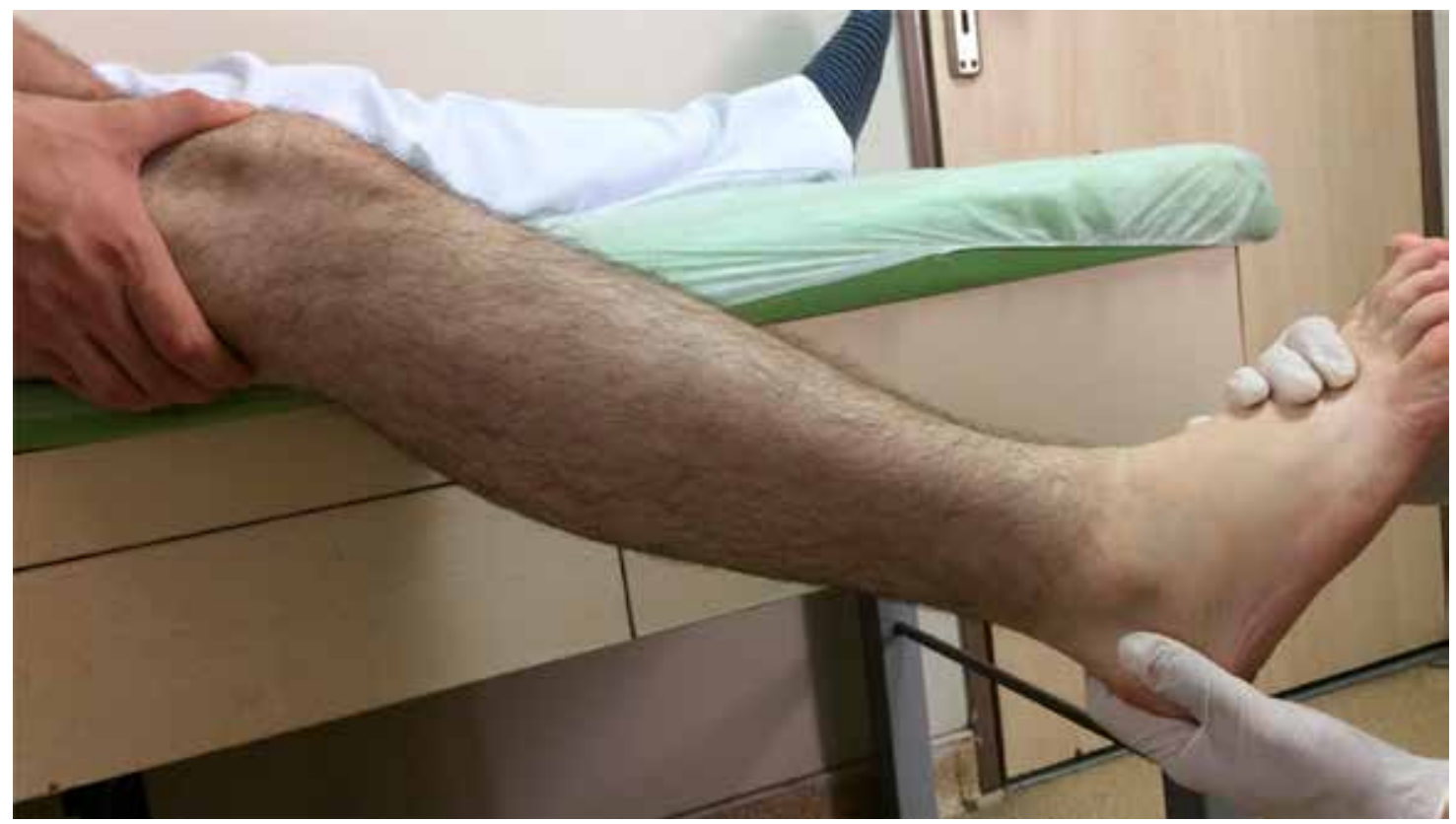

Şekil 1. Ayaktan ve topuktan uygulanan traksiyon.

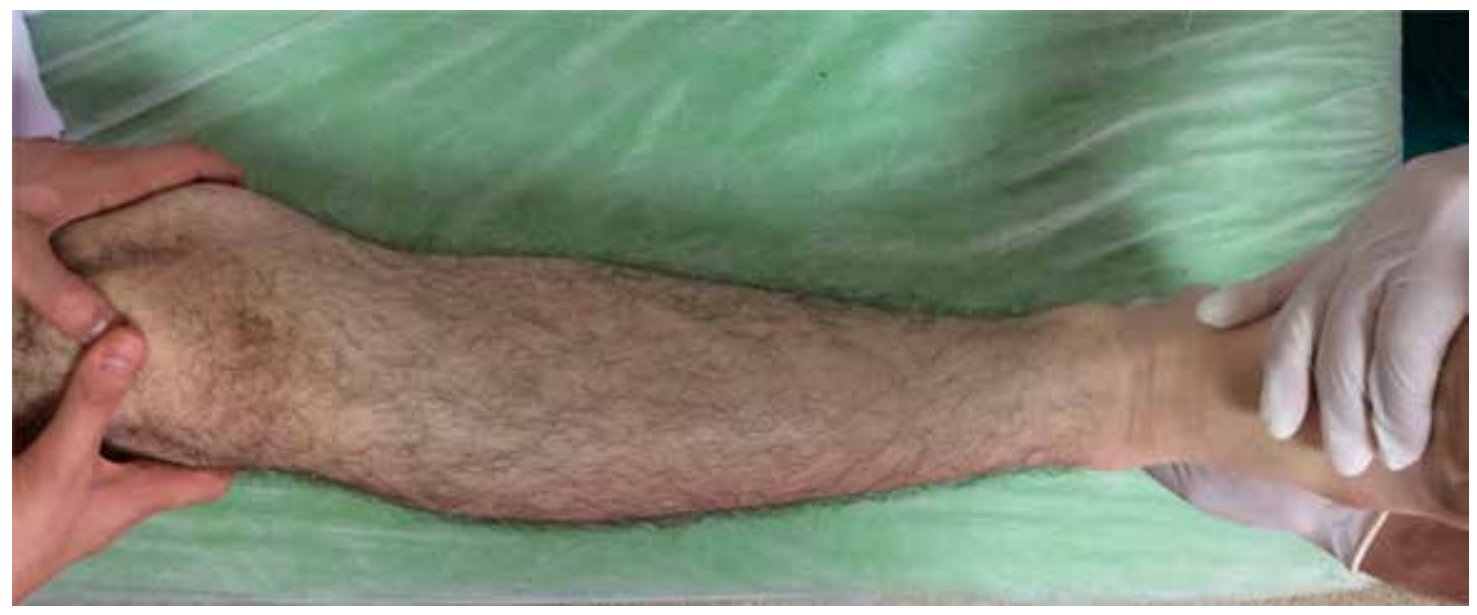

Şekil 2. Rotasyonun ayarlanması için ayak aksı ve uyluk açısının değerlendirilmesi.

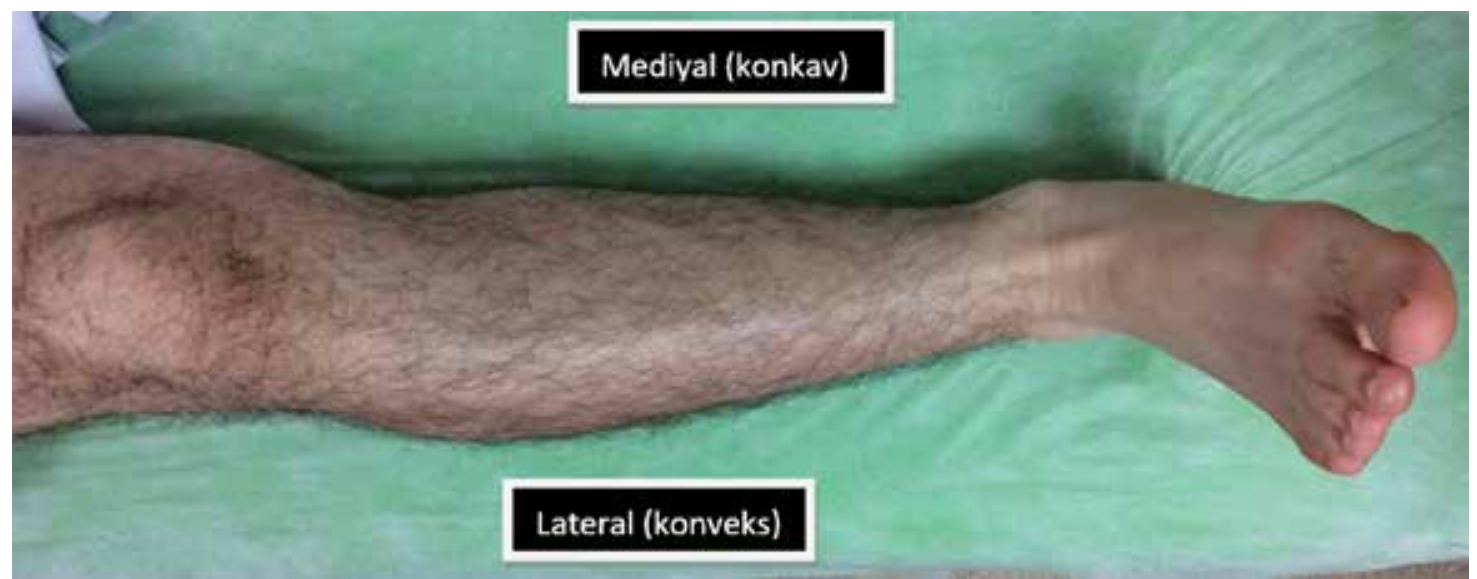

Şekil 3. Uygun yerleştirilmiş tibia kırığının lateralde konveks, mediyalde konkav görünümü. 


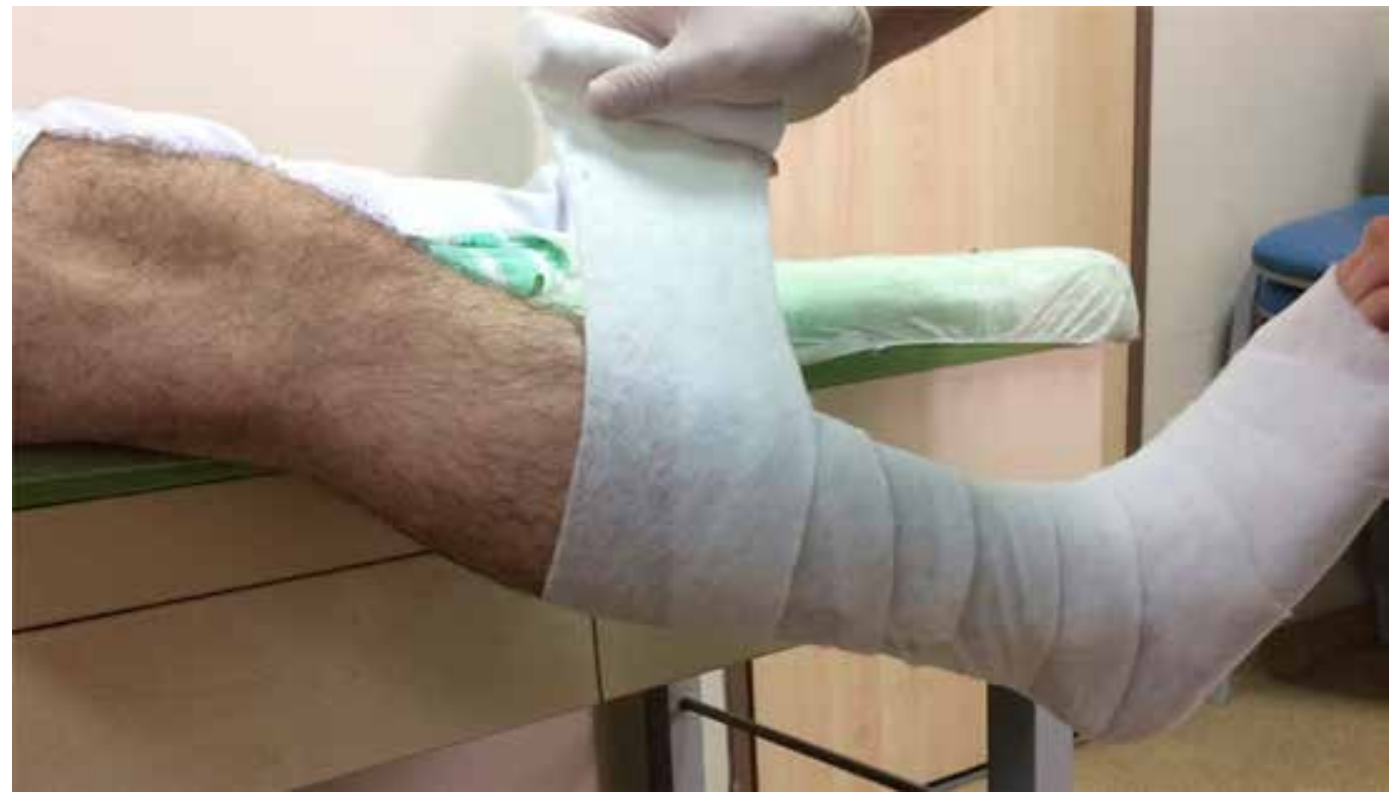

Şekil 4. Alçı pamuğunun \%50 üstüste gelecek şekilde sarılması.

- Kemiksel çıkıntıların olduğu noktalar (malleoller, fibula başı) gerekirse birkaç kat pamuk ile sarilır.

- Alçıyı ıslatmak için sıcak su kullanılmamalıdır. Bir elle alçının açık ucu, diğer elle rulo tutularak ve hava köpükleri bitene kadar suda tutulur.

- Alçı sudan çıkarılıp rulo sıkılır ve sarılırken bir önceki genişliğin 2/3'ünü kapatacak şekilde sarılır.

- Alçı sarılırken, pamuk tabakasının alçı tabakası arasına girmemesine dikkat edilmelidir.

- Daha sonra avuç içi ile sıvazlanarak alçının düzgün bir şekil alması sağlanır. Alçı üzerinde hiçbir zaman parmak uçlarıyla direkt basıya neden olacak şekilde katlantı oluşmasına izin verilmemelidir.

- Ardından, diğer katlar sarılarak istenilen pozisyonda alçının donması için beklenir.

- Eğer herhangi bir yara varsa bu kısımlar belirlenerek, yara bakımı için kapak açılmalıdır.

- Alçı tamamen donana dek, bacak elevasyonda ve aynı pozisyonda tutulmalıdır.

- Alçının diz çevresinde en zayıf alana sahip olduğu ve bu bölgenin kuvvetlendirilmesi gerektiği unutulmamalıdır.

\section{DIZALTI ALÇI}

$\mathrm{Bu}$ alçı, alt ekstremitenin ayak bileği kırıkları, ayak kırıkları ve yumuşak doku yaralanmaları için sıklıkla kullanılır. Basit pilon kırıkları veya distal tibia diyafız kırıkları için de bazen kullanılır. Alçı, proksimalde fibula boynundan distalde metatars başlarına kadar, ayak bileği $90^{\circ}$ 'de ve ayak plantigrad pozisyonda olacak şekilde uygulanır (Şekil 5). Dizaltı alçı, instabil tibia diyafız kırıklarında kullanılan uzun bacak alçılamanın ilk aşaması olarak da uygulanabilir. ${ }^{[1]}$

Hasta bir masa kenarında oturtulur ve dizler $90^{\circ}$ fleksiyonda iken alçı uygulanır. Malleoller çıkıntılı bölgeler oldukları için ilave pamuk sarılması gerekebilir. Ayak bileği nötral $90^{\circ}$ 'de olacak şekilde alçı yapılır. Alçı, distalde metatarsofalangeal ekleme, proksimalde ise tuberositas tibianın $1 \mathrm{~cm}$ distaline kadar uzatılır. Proksimal ve distalde alçının bittiği seviyeyi geçen pamuk kısımları alçının üzerine katlanır, alçının bitiş noktalarının cildi rahatsız etmesi önlenir. ${ }^{[3]}$

\section{DizÜSTÜ ALÇı}

Uzun bacak alçılama instabil tibia diyafiz kırıklarının tedavisinin akut fazında kullanılabilir ve birkaç hafta sonra kaynama dokusunun görülmesini takiben PTB alçı ile hasta takibi yapılabilir. Ayrıca, diz çevresi kırıklarının tedavisinde de kullanılabilir. Uzun bacak alçııı yapmanın en kolay yöntemi öncelikle kısa bacak alçı yapılması ve sonrasında diz $20-30^{\circ}$ fleksiyona alınarak uyluğun alçılanmasıdır. ${ }^{[1]}$ 

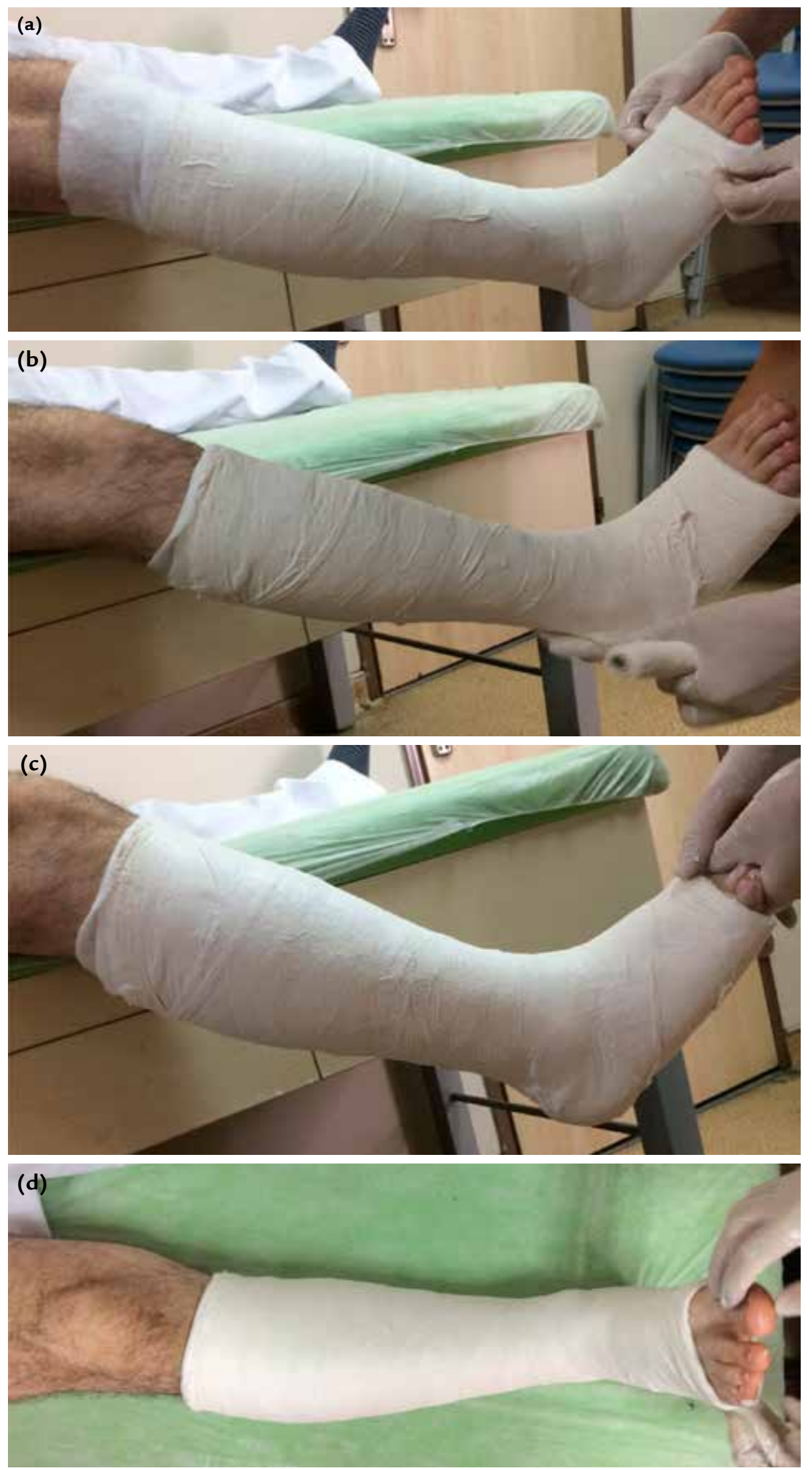

Şekil 5. a-d. Dizaltı alçı uygulaması. 

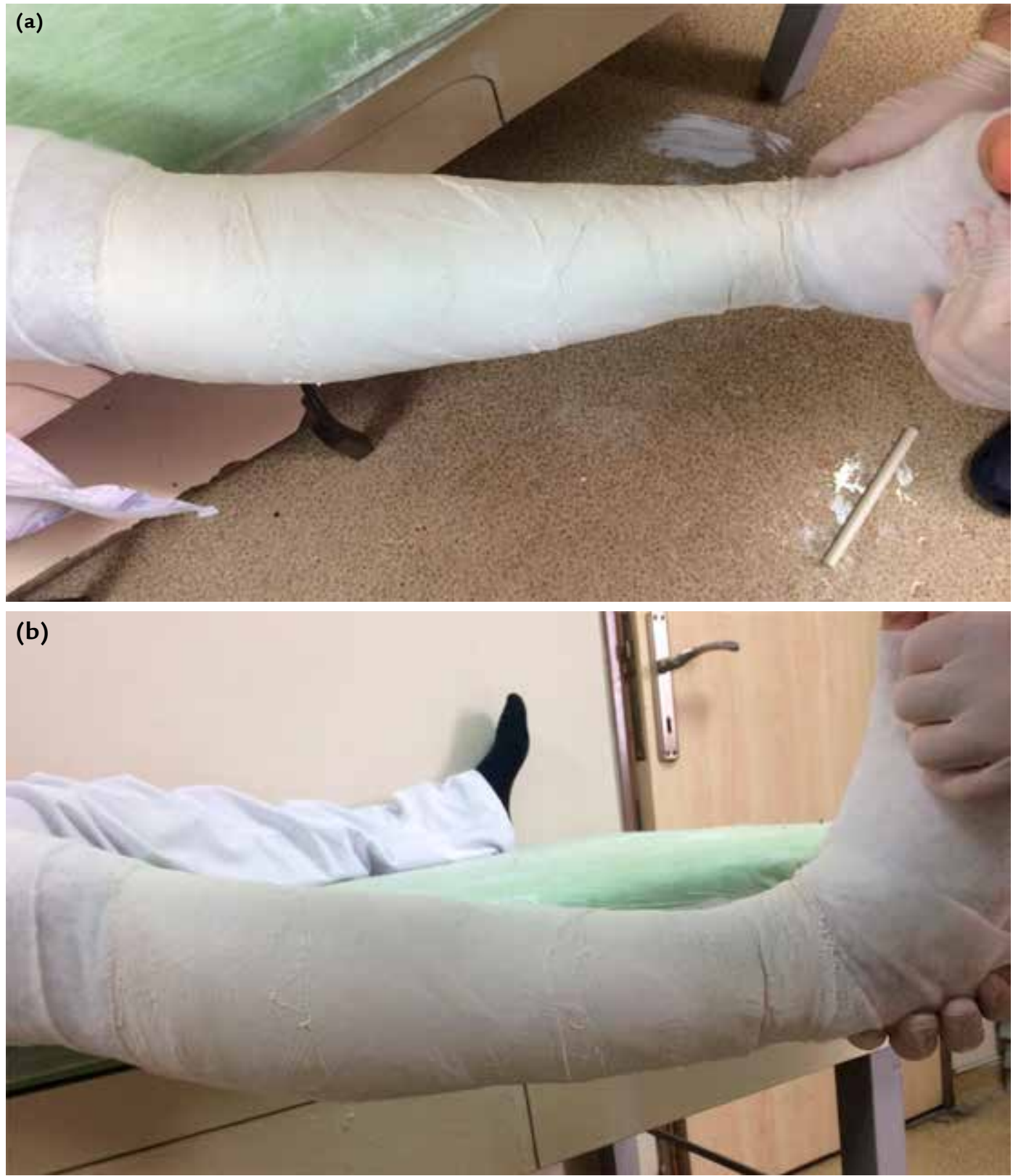

Şekil 6. a, b. Dizüstü alçının ilk aşamasının yapılışı.

Örneğin; tibia cisim kırığı için kırık redüksiyonu yapıldıktan sonra hastanın kırık olan ekstremitesi müdahale masasından aşağı doğru sarkıtılır. Diz, gastro-soleus kaslarının gevşeyip manipülasyon ve traksiyona izin vermesi için fleksiyona alınır. Eğer mümkünse ya da gerekliyse, skopi ile pozisyon kontrol edilir. Uygun pozisyonda ayaktan traksiyona devam ediliyorken, bir yardımcı tarafından önce kırık bölgesi merkez alınarak, ayak bileği ve diz arası kruris alçılanır. Alçı donup kırık tespit edildikten sonra, pamuk ve takibinde alçı, ayak bileği ve ayağa doğru metatarsofalangeal eklem seviyesine dek devam ettirilir. Parmak dorsifleksiyonuna engel olmamak için, metatarsofalangeal eklemin dorsumunun alçı ile kapatılmamasına özen gösterilmelidir. Bu sırada, ayak nötral rotasyonda ve ayak bileği nötral pozisyonda $90^{\circ}$ 'de olmalıdır (Şekil 6). Ardından, alt ekstremite sedye üzerinde yumuşak bir yastığa yerleştirilerek, diz eklemi $30^{\circ}$ fleksiyonda olacak şekilde alçı yapımı tamamlanır (Şekil 7). Alçı donunca anterior-posterior $(\mathrm{AP})$ ve lateral iki yönlü röntgen veya skopi ile kırık pozisyonu kontrol edilir. Kırıkta bir açılanma 

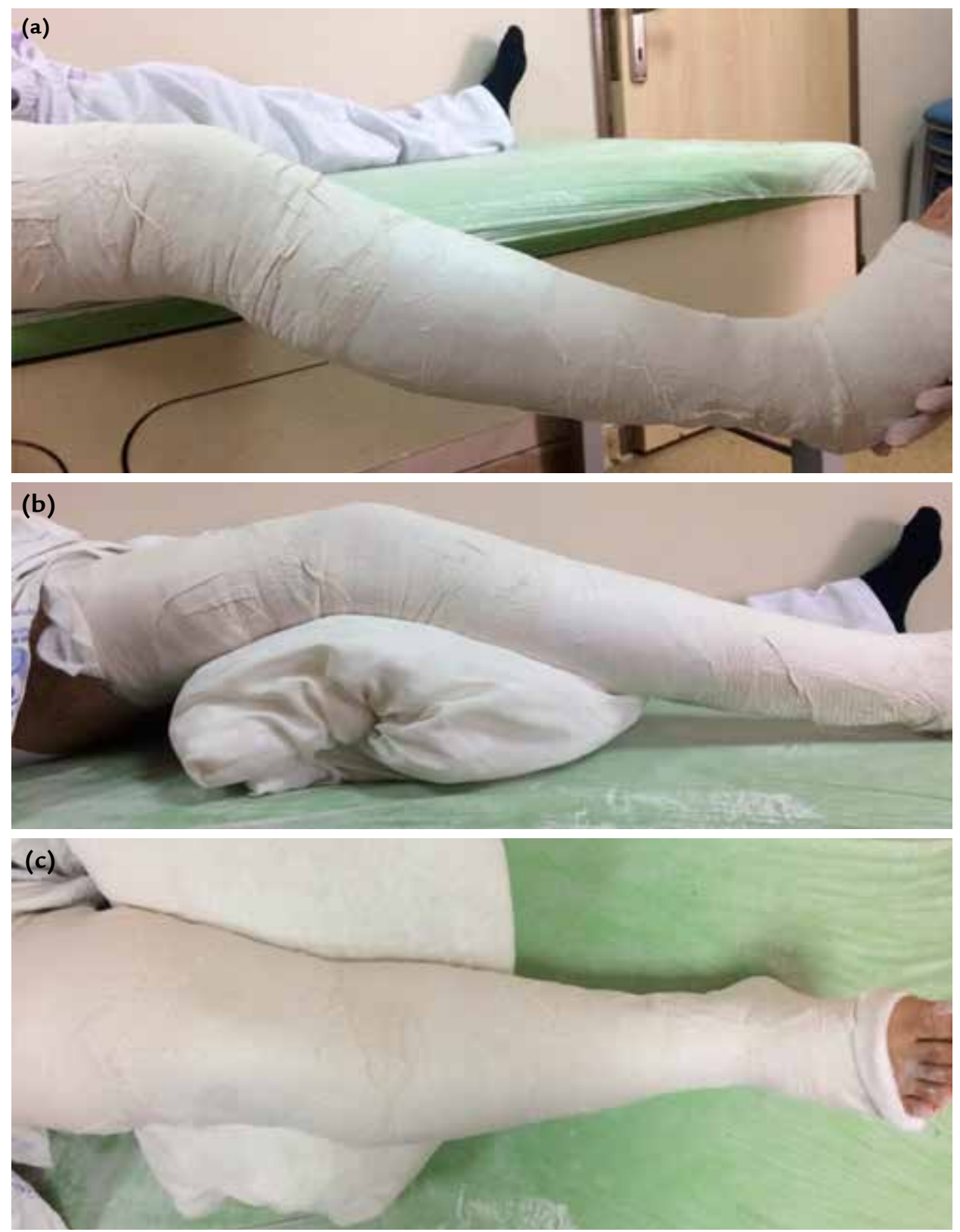

Şekil 7. a-c. Dizüstü alçının ikinci aşamasının yapılışı.

mevcutsa ya da takipler sırasında herhangi bir açılanma meydana gelirse, açlanmanın olduğu hizadan kama ekleme veya kama çıkarma işlemi yapılıp, bu bölge tekrar alçı ile güçlendirilebilir. Kırık pozisyonu uygun ise, hastaya alçı bakımı, elevasyon, dolaşım takibi, parmak aktif egzersizleri, düz bacak kaldırma egzersizleri hakkında bilgi verilerek evine gönderilebilir. Kompartman sendromu bulguları olan kırıkla orantılı olmayan ağrı, parmaklarda şişme, morarma, solukluk, uyuşma gibi şikâyetleri olursa, hastaya vakit kaybetmeden hastaneye başvurması gerektiği ayrıntılı olarak anlatılmalıdır. Alçı uygulaması sonrası 24 saat içinde, hasta mutlaka ortopedi hekimi tarafından dolaşım kontrolü için tekrar değerlendirilmelidir. Bu kontrolün ardından, normal koşullarda bir miktar denge elde edilinceye dek (3-4 hafta) haftalık takip etmek gerekir. Dört ila altı hafta sonra, kırık iyileşmesi uygun ise alçı diz altına inilebilir veya PTB (patellar tendon taşıyıcı) alçı yapılarak hastanın ekstremitesine yük vermesine izin verilebilir. Bu tespit, yeterli kaynama dokusu görülünceye kadar devam ettirilmelidir. ${ }^{[4]}$ 

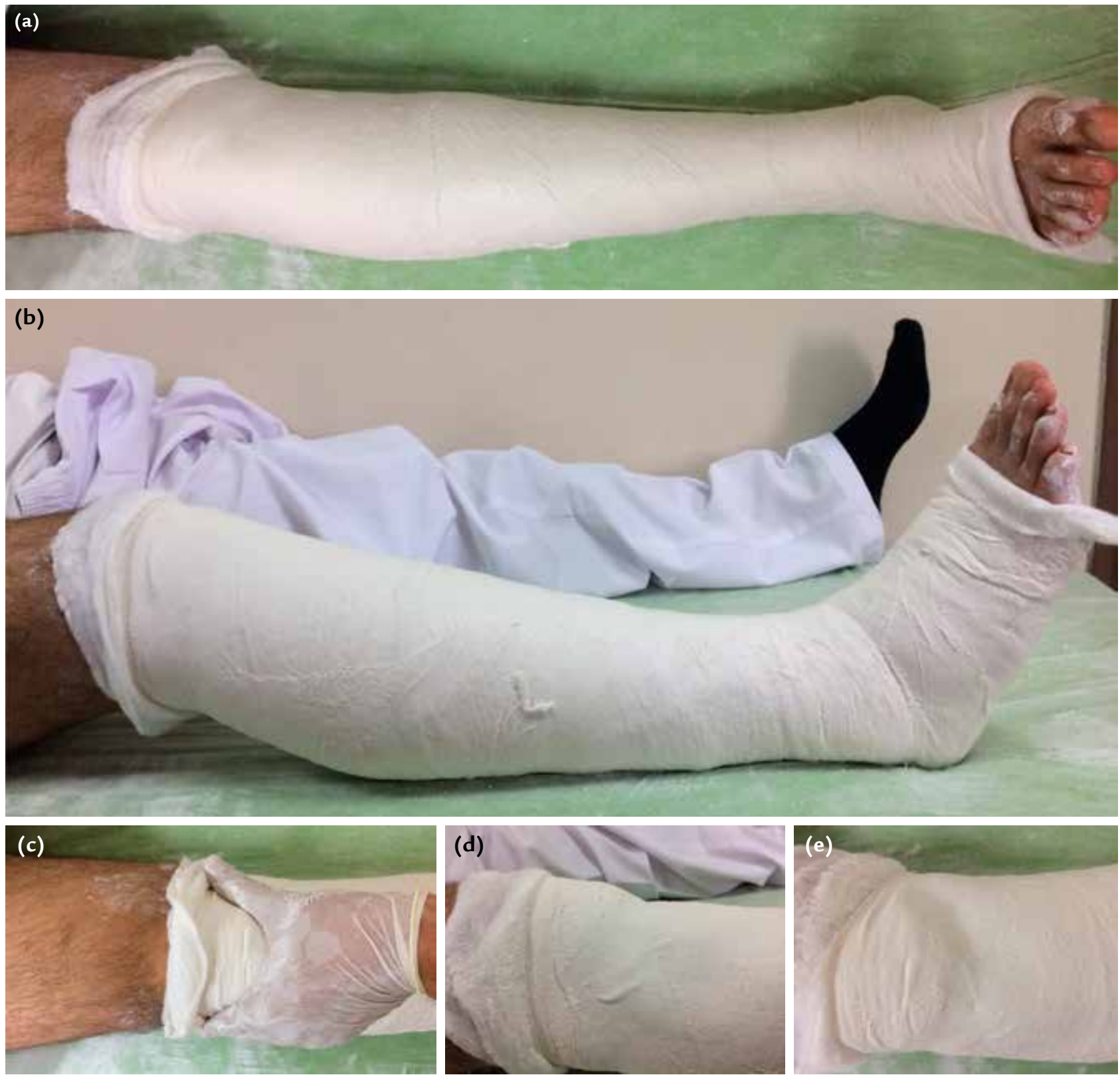

Şekil 8. a-e. Patellar tendon taşıyıcı (PTB) alçı.

\section{PATELLAR TENDON TAŞIYICI (PTB) ALÇI}

Dizaltı alçının bir diğer çeşidi, patellar tendon destekleyici alçıdır. Sıklıkla, birkaç hafta süreyle uzun bacak alçıda kalmış olan tibia diyafiz kırıklarının tedavisinde kullanılır. Bu alçıda, kısa bacak alçının proksimal sınırı patellanın alt polüne kadar uzanır ve rotasyonel stabilite derecesini elde edebilmek için patellar tendon çevresinde şekil verilir (Şekil 8). Fibula boynu çevresinde peroneal sinir üzerine basınç uygulanmamasına dikkat edilmelidir. ${ }^{[1]}$

\section{ALÇININ AÇILMASI}

Ekstremitede belirgin bir şişme söz konusu ise alçı mutlaka açılmalıdır. Alçı hala nemli ise alçının altına cildi koruyucu bir materyal (alüminyum bir levha, abeslang vb.) yerleştirilerek alçı makası ile alçı açılabilir. Alçı kurumuş ise, alçı motoru dikkatli bir şekilde kullanılarak alçı açılmalıdır. Dolaşımın rahatlaması için alttaki pamuk tabakası da mutlaka kesilmelidir. 


\section{KOMPARTMAN SENDROMU}

Yeterli pamuk desteğinin yapılmadı̆̆ı veya alçının sıkı bir şekilde sarıldığı tüm olgular kompartman sendromu açısından risk taşımaktadır. Eğer hastada kırık ile orantılı olmayan bir ağrı, pasif parmak dorsifleksiyonu ile ağrının artması, parmaklarda solukluk, renk değişikliği ve ödem söz konusu ise, alçı, pamuk ve alçı çorabı mutlaka hızlı bir şekilde açılmalı ve bacak dolaşımı rahatlatılmalıdır. Hasta mutlaka hastaneye yatırılmalı, kompartman sendromu bulguları seri muayenelerle değerlendirilmeli ve hasta dosyasına not edilmelidir. Şüphe durumunda mutlaka acil fasyatomi yapılmalı ve kompartman içi basıncın düştüğünden emin olunmalıdır.

\section{KAYNAKLAR}

1. Court-Brown CM. Principles of Nonoperative Fracture Treatment. In: Bucholz RW, Heckman JD, Court-Brown CM, Tornetta P, editors. Rockwood and Green's Fractures in Adults, 7th ed. Philadelphia PA: Lippincott Williams \& Wilkins; 2009. p.124-61.

2. Milli Eğitim Bakanlığı, Ortopedik Protez ve Ortez Alt Ekstremite Alçısı 725TTT037 Ankara, 2011. http://megep. meb.gov.tr/mte_program_modul/moduller_pdf/Alt\%20 Ekstremite\%20Al\%C3\%A7\%C4\%B1s\%C4\%B1.pdf

3. Swiontkowski MF, editor. Alçı ve Bandajlama Teknikleri. İçinde: Yakut Y (Çev.). Ortopedi El Kitabı, 5. Baskı. Güneş Kitabevi; 2003. p.85-103.

4. Aşık M. Tibia ve Fibula Cisim Kırıkları. İçinde: Alturfan AK, editör. Ortopedik Travmatoloji. İstanbul: Nobel Tıp Kitabevleri; 2002. p.311-28. 